\title{
Negative Pressure Pulmonary Hemorrhage after Laryngospasm during the Postoperative Period
}

\author{
In Soo Han, Bo Mi Han, Soo Yeon Jung, Jun Rho Yoon, Eun Yong Chung \\ Department of Anestheiology and Pain Medicine, College of Medicine, The Catholic University of Korea, Seoul, Korea
}

Negative pressure pulmonary hemorrhage (NPPH) is an uncommon complication of upper airway obstruction. Severe negative intrathoracic pressure after upper airway obstruction can increase pulmonary capillary mural pressure, which results in mechanical stress on the pulmonary capillaries, causing NPPH. We report a case of acute NPPH caused by laryngospasm in a 25-year-old man during the postoperative period. Causative factors of NPPH include negative pulmonary pressure, allergic rhinitis, smoking, inhaled anesthetics, and positive airway pressure due to coughing. The patient's symptoms resolved rapidly, within 24 hours, with supportive care.

Key Words: airway obstruction; hemoptysis; hemorrhage

Laryngospasm in the perioperative period most commonly occurs during the induction of anesthesia or during extubation [1]. Incidence of laryngospasm has been under $1 \%$ in both adults and children [2]. It can be rapidly and effectively treated by removing irritant stimulus, increasing anesthetic depth, and providing continuous positive airway pressure with $100 \%$ oxygen $[1,3]$. Despite such procedures, abrupt airway obstruction and its relief can result in negative pressure pulmonary edema (NPPE) and negative pressure pulmonary hemorrhage (NPPH) $[1,4,5]$. Here we report a case of a 25 -year-old man who suffered from NPPH following postextubation laryngospam.

\section{CASE REPORT}

A healthy 25 -year-old man of $178 \mathrm{~cm}$ and $70 \mathrm{~kg}$ was scheduled to undergo testis repair for a traumatic testicular rupture. He was a smoker with allergic rhinitis. His preoperative findings were unremarkable. General anesthesia was induced with thiopental $300 \mathrm{mg}$ and succinylcholine $70 \mathrm{mg}$ using a rapid sequence technique. Rocuronium $50 \mathrm{mg}$ was administered for muscle relaxation. Endotracheal intubation was conducted easily and atraumatically. Anesthesia was maintained with oxygen $1.5 \mathrm{l} / \mathrm{min}$, air $2.5 \mathrm{l} / \mathrm{min}$, desflurane $5-7 \mathrm{vol} \%$, and remifentanil $0.1-0.25 \mu \mathrm{g} / \mathrm{kg} / \mathrm{min}$. He was hemodynamically stable throughout the surgical procedure which lasted 1 hour. During the operation, $350 \mathrm{ml}$ of hartmann solution was administered. Once spontaneous respiration resumed, he was given sugammadex 200 mg for muscle recovery. He was extubated uneventfully. Immediately after extubation, however, he became agitated and developed marked respiratory distress with decreased

\section{Case Report}

Received: August 4, 2016 Revised: September 26, 2016 Accepted: September 30, 2016

\section{Corresponding author}

Eun Yong Chung

Department of Anestheiology and Pain Medicine, Bucheon St. Mary's Hospital, College of Medicine, The Catholic University of Korea, 327 Sosa-ro, Wonmi-gu, Bucheon 14647, Korea

Tel: +82-32-340-2158

Fax: +82-32-340-2255

E-mail:anes36@catholic.ac.kr

Copyright $@ 2018$ The Korean Society of Critical Care Medicine

This is an Open Access article distributed under the terms of Creative Attributions Non-Commercial License (http:// creativecommons.org/li-censes/by-nc/4.0/) which permits unrestricted noncommercial use, distribution, and reproduction in any medium, provided the original work is properly cited. 


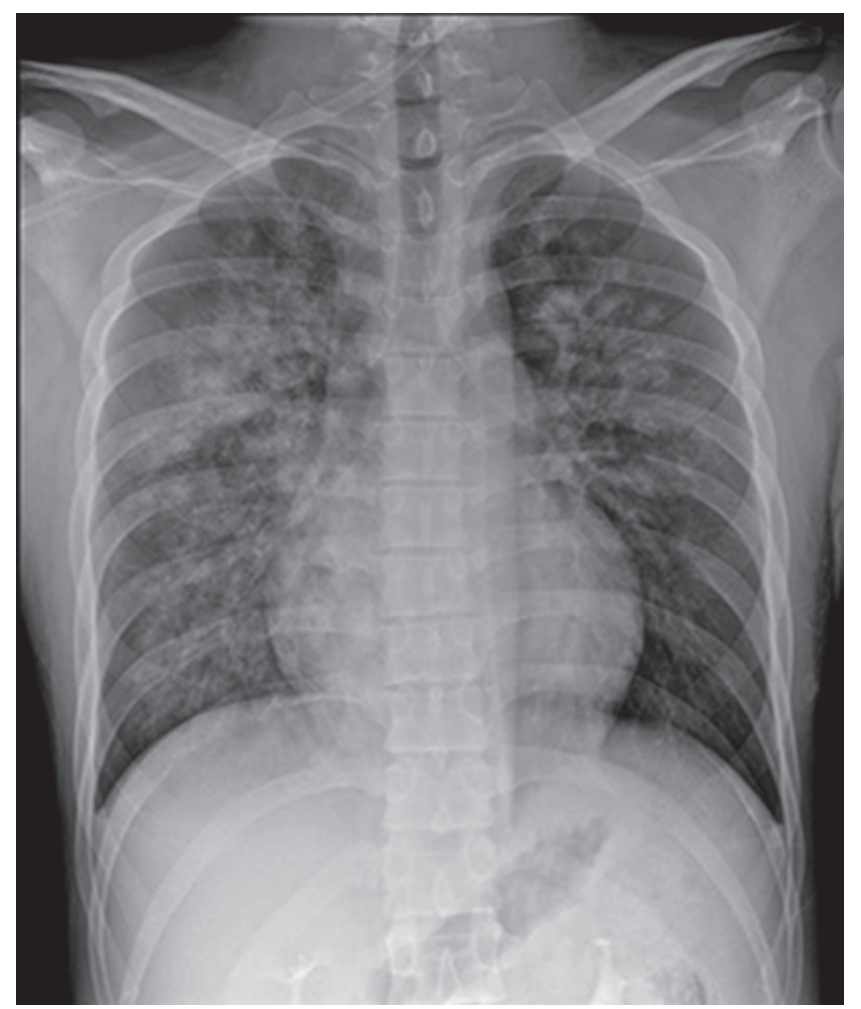

Figure 1. Immediate postoperative chest $X$-ray showing bilateral central patchy infiltrates and ground glass opacities. oxygen saturation $\left(\mathrm{SpO}_{2}\right)$ at $42 \%$. We thought that laryngospasm had developed due to an abrupt upper airway obstruction. He was immediately treated with $100 \%$ oxygen positive pressure and mask ventilation. His $\mathrm{SpO}_{2}$ was improved to $97 \%$ within a few minutes. The patient was stabilized and transferred to the Post- Anesthesia Care Unit (PACU).

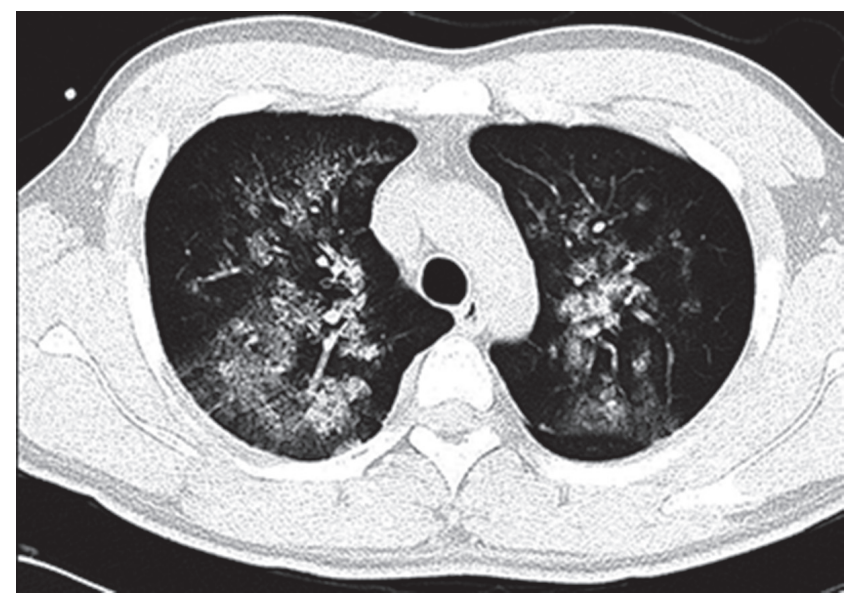

Figure 2. Immediate postoperative enhanced chest computed tomography showing bilateral consolidations and ground glass opacities in the central and middle lung zones of both lobes.
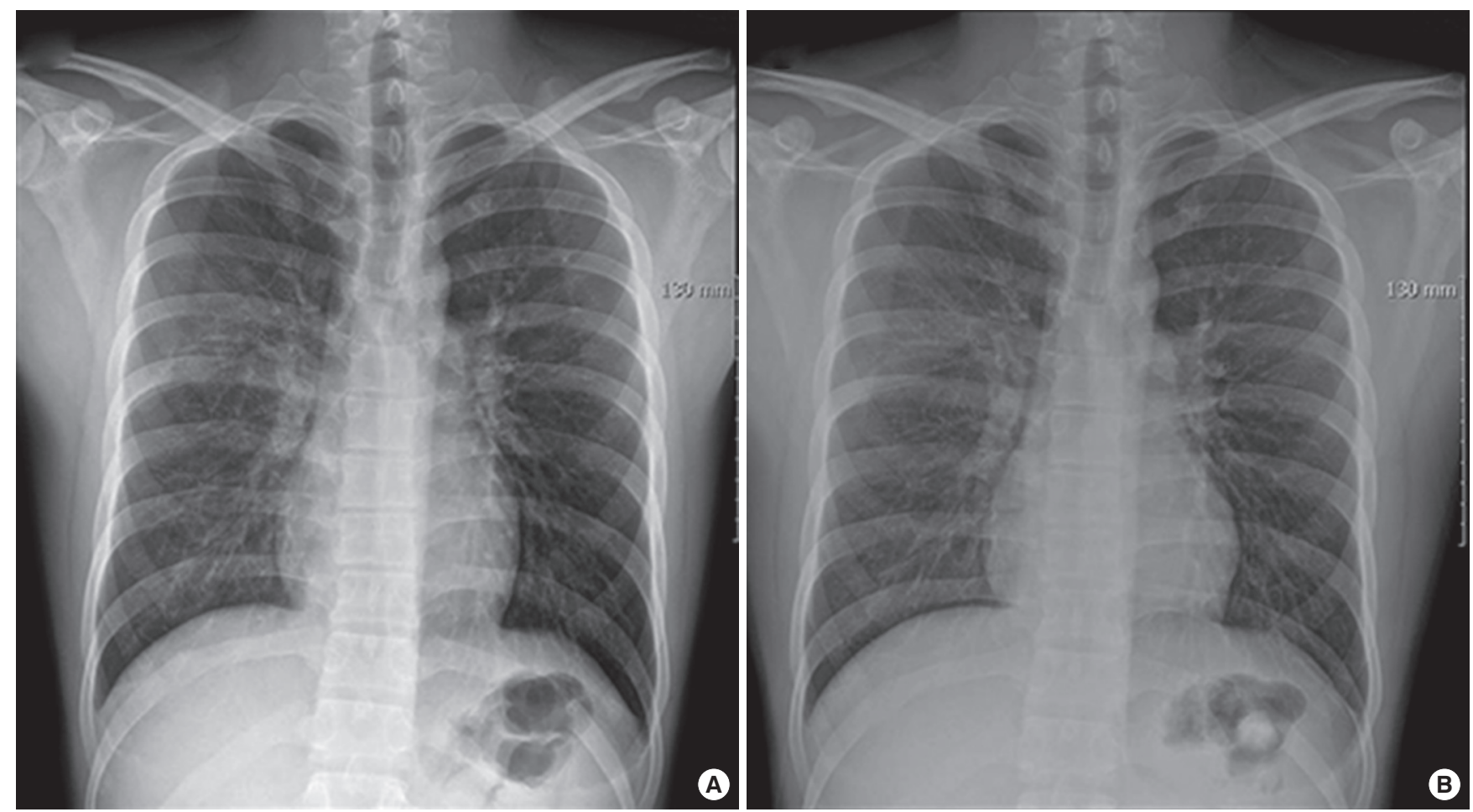

Figure 3. Chest X-ray showing interval regression of bilateral diffuse central ground glass opacities and subtle remaining patchy ground glass opacities in the right upper lobe area on the 1st postoperative day $(A)$, and resolution of the pulmonary infiltrates on the 3rd postoperative day (B). 
On arrival at the PACU, the patient was placed on $100 \%$ supplemental oxygen via facemask. Twenty five minutes later (40 minutes after postextubation laryngospasm), he developed severe cough and hemoptysis of approximately $50 \mathrm{ml}$. His $\mathrm{SpO}_{2}$ again fell to $80 \%$ to $90 \%$. He revealed acute distress symptoms and had vital signs of sympathetic hyperactivity with blood pressure of $170 / 80 \mathrm{mmHg}$ and heart rate of 105 beats/min. In the PACU, the patient continued to expectorate blood (hemoptysis of approximately a cup) for 45 minutes. Arterial blood gas analysis showed $\mathrm{pH} 7.36, \mathrm{PaCO}_{2} 49 \mathrm{mmHg}$, $\mathrm{PaO}_{2} 55 \mathrm{mmHg}, \mathrm{Hb}$ 16.3, and oxygen saturation of $87 \%$. Portable chest radiograph showed diffuse bilateral pulmonary infiltrate (Figure 1). After the patient took a turn for the better, he was transferred to the Intensive Care Unit (ICU). Department of medicine consult was requested. Immediate chest computed tomographic scan images showed ground grass opacity and induration with the appearance of alveolar infiltrates in both lungs (Figure 2). After continuous hemoptysis, his hemoglobin level dropped from 16.3 to $14.0 \mathrm{~g} / \mathrm{dl}$. He had no abnormalities in immunologic laboratory tests. The patient was stabilized progressively in the ICU with supportive management. Bronchoscopy was deferred as he became better. One day after the operation, symptoms and chest infiltrates resolved. He was transferred back to the general ward with nasal prong supplying $3 \mathrm{l} / \mathrm{min}$ oxygen (Figure $3 \mathrm{~A}$ ). Two days later, pulmonary infiltrates improved completely on the chest radiograph (Figure 3B). On postoperative day 4, the patient was discharged with $\mathrm{SpO}_{2} 99 \%$ on room air.

\section{DISCUSSION}

NPPE due to acute upper airway obstruction following extubation has been well-reported $[4,6]$. But, pulmonary hemorrhage by upper airway obstruction rarely occurs. Schwartz et al. [7] released the first case of NPPH due to upper airway obstruction in 1999. Since then, it has been reported occasionally $[3,5]$. Papaioannou et al. [8] have described that true hemoptysis is due to negative pressure tracheobronchial injury, whereas alveolar hemorrhage is a very rare expression of severe NPPE.

Risk factors for developing upper airway obstruction in the postoperative period include obesity, short neck, obstructive sleep apnea, difficult intubation, acromegaly, and upper airway surgery [9]. Any condition that causes the upper airway obstruction can occur postobstructive pulmonary edema, and laryngospasm seems to be the most common cause of that in the PACU $[6,9]$. Young male athletes are at risk because of ability to generate significant inspiratory force. Other conditions include aggressive tracheobronchial suction, laryngeal mask malposition, and biting of the endotracheal tube [10]. As far as possible in this case, aspiration of secretions, fluid overload, occulsion of endotracheal tube, and anaphylaxis were excluded.

The symptoms of NPPE usually develops immediately after extubation but may occur after several hours. Signs and symptoms of NPPE include restlessness, agitation, cyanosis, and pink frothy pulmonary secretions $[9,10]$. Among them, the foam, pinkish pulmonary sputum is the characteristic sign of NPPE [9]. Another symptom is hemoptysis [3,4], which in the setting of NPPE implies capillary failure and alveolar hemorrhage $[5,7,11]$. As a result of acute airway obstruction, pulmonary edema and hemorrhage occurred simultaneously in several reports $[3,4,8]$, whereas hemorrhage just had to occur in this case. Laryngospasm occurred after tracheal extubation and did not predict the possibility of NPPE. But, decreased oxygen saturation, continuous pulmonary hemorrhage with a decreased hematocrit, and bilateral diffuse alveolar consoliation on chest radiograph reminded us of NPPH. In this case, frank hemoptysis occurred 40 minutes after postoperative airway obstruction. He had mild chest discomfort and 95\%-96\% of $\mathrm{SpO}_{2}$ during the first 25 minutes of PACU, and then developed severe cough and hemoptysis without pink frothy pulmonary secretion. After that, he continued to expectorate blood with acute respiratory distress symptoms (tachypnea, shortness of breath, agitation, $80 \%-90 \%$ of $\mathrm{SpO}_{2}$ ) for $45 \mathrm{~min}$ utes, but had no pink frothy sputum. So we consider frank hemorrhage rather than NPPE.

In this case, the abrupt onset of obstruction was most likely caused by laryngospasm. Laryngospasm commonly occurs after extubation if the endotracheal tube is removed when reflexes of patients are hyperactive or when patients are awake. When laryngospasm occurs, the vocal cords may close and the ventilation may not be possible. Life-threatening hypoxia, post-obstructive pulmonary edema, and cardiac arrest can occur. During laryngospasm, subatmospheric intrathoracic pressure can increase both intracardiac pressures and bronchial vascular resistance through pulmonary, hyperadrenergic, and cardiac mechanisms [12]. As a result, bronchial vasculature may be injured, causing focal hemorrhages in the tracheobronchial tree. Schwartz et al. [7] have postulated that generation of markedly negative intrathoracic pressure may cause membrane defects leading to alveolar hemorrhage. The actual negative pressure threshold for pulmonary microvasculature disruption remains unknown in humans. In rabbit 
model, microvasculature pressure of nearly $40 \mathrm{mmHg}$ induced stress failure [13]. In our case, the initial manifestation of pulmonary or airway injury was frank blood rather than frothy fluid, suggesting NPI or NPPH rather than NPPE.

Diagnosis of NPPE and NPPH is usually made on the basis of a history of a precipitating incident and symptoms. Thoracic computed tomography, magnetic resonance imaging, and bronchoscopy are used to the diagnosis of pulmonary hemorrhage $[5,8,14]$. Among them, bronchoscopy and bronchoalveolar lavage are necessary for precise diagnosis $[4,15]$. In addition, evaluation of hemosiderophages from bronchoscopic biopsy is useful for chronicity $[8,16]$. Typical radiologic findings of NPPH are infiltrates of central and nondependent regions $[5,17]$. Computed tomography display central and nondependent distribution of ground glass attenuation. Dyspnea and decreased saturation occurred simultaneously in present pulmonary hemorrhage, and chest radiograph showed bilateral infiltrates. We could not find the site of bleeding since he refused bronchoscopy and hemoptysis was decreased gradually during the early postoperative period.

NPPH require immediate attention in PACU. Treatment for NPPH is supportive care, including airway control, hemodynamic stabilization, and determining the nature and source of bleeding. The use of diuretics and steroids is controversial. NPPH can be considered as clinical improvement within 1224 hours [12,17]. Our patient was also improved within 24 hours. Indeed, the absence of radiolographic abnormalities or symptoms during followup interval indicated that our patient's hemoptysis was not caused by preexisting pulmonary or endobronchial lesions, but by negative pressure injury.

Prevention of upper airway obstruction can reduce the incidence. Preventive measures include lidocaine 3-5 minutes before extubation for preventing laryngospasm, atropine to reduce secretions, steroid in patients who are at risk [9]. In order to prevent and reduce the incidence of NPPE and NPPH, it is important to handle airway gently, suck oral secretion carefully, and extubate at the proper time.

Although our patient might have developed NPPH, his clinical manifestation and process were coincides with diffuse alveolar hemorrhage, an extremely rare phenomenon originating from alveolar microcirculation. Diffuse alveolar hemorrhage includes hemoptysis, anemia, diffuse lung infiltration, and acute respiratory failure [14]. It is associated with many drugs and numerous diseases including chemotherapy, bone marrow transplantation, and autoimmune disorders [16]. It can occur after vigorous exercise or barotrauma during general anesthesia [5]. Case reports have described diffuse al- veolar hemorrhage induced by inhaled anesthetics [15,18]. In our patient, he had cough, hemoptysis, a drop in the hematocrit, and diffuse lung infiltration, but no history about immune or collagenous diseases. He had no clinical or serological evidence of an underlying systemic disease. However, we could not rule out diffuse alveolar hemorrhage because the patient refused bronchoscopy.

Negative pressure injury rather than NPPE was considered as the chief problem in our case. Airway pressure changes might have injured tracheobronchial vessels, predisposing to airway bleeding when the patient coughed during emergence. Conceivably, cigarette smoking and allergic rhinitis might have increased the friability of vascular mucosa, thus increasing the susceptibility to negative pressure injury. Also, we speculate that airway irritation during desflurane might have manifested by salivation, coughing, and laryngospasm, resulting in barotrauma and pulmonary hemorrhage.

In conclusion, severe negative ITP may occur due to postextubtion upper airway obstruction, resulting in pulmonary hemorrhage with or without pulmonary edema. This uncommon complication should be taken into careful consideration in perioperative evaluation.

\section{CONFLICT OF INTEREST}

No potential conflict of interest relevant to this article was reported.

\section{ORCID}

Eun Yong Chung http://orcid.org/0000-0003-0811-9578

\section{REFERENCES}

1. Gavel G, Walker RW. Laryngospasm in anaesthesia. Contin Educ Anaesth Crit Care Pain 2014;14:47-51.

2. Olsson GL, Hallen B. Laryngospasm during anaesthesia: a computer-aided incidence study in 136,929 patients. Acta Anaesthesiol Scand 1984;28:567-75.

3. Bhavani-Shankar K, Hart NS, Mushlin PS. Negative pressure induced airway and pulmonary injury. Can J Anaesth 1997; 44:78-81.

4. Koch SM, Abramson DC, Ford M, Peterson D, Katz J. Bronchoscopic findings in post-obstructive pulmonary oedema. Can J Anaesth 1996;43:73-6.

5. Broccard AF, Liaudet L, Aubert JD, Schnyder P, Schaller MD. Negative pressure post-tracheal extubation alveolar hemor- 
rhage. Anesth Analg 2001;92:273-5.

6. Mulkey Z, Yarbrough S, Guerra D, Roongsritong C, Nugent K, Phy MP. Postextubation pulmonary edema: a case series and review. Respir Med 2008;102:1659-62.

7. Schwartz DR, Maroo A, Malhotra A, Kesselman H. Negative pressure pulmonary hemorrhage. Chest 1999;115:1194-7.

8. Papaioannou V, Terzi I, Dragoumanis C, Pneumatikos I. Negative-pressure acute tracheobronchial hemorrhage and pulmonary edema. J Anesth 2009;23:417-20.

9. Davidson S, Guinn C, Gacharna D. Diagnosis and treatment of negative pressure pulmonary edema in a pediatric patient: a case report. AANA J 2004;72;337-8.

10. Zhurda T, Muzha D, Dautaj B, Marku F, Kurti B, Jaho E, et al. Acute posoperative negative pressure pulmonary edema as complication of acute airway obstruction: case report. J Anesth Clin Res 2016;7:603-6.

11. Patel AR, Bersten AD. Pulmonary haemorrhage associated with negative-pressure pulmonary oedema: a case report.
Crit Care Resusc 2006;8:115-6.

12. Diab K, Noor A. Negative pressure pulmonary hemorrhage. Respir Med CME 2009;2:170-2.

13. West JB, Tsukimoto K, Mathieu-Costello O, Prediletto R. Stress failure in pulmonary capillaries. J Appl Physiol (1985) 1991;70:1731-42.

14. Park MS. Diffuse alveolar hemorrhage. Tuberc Respir Dis (Seoul) 2013;74:151-62.

15. Khanna AK, Cummings KC 3rd. Pulmonary hemorrhage in an outpatient ophthalmic anesthesia setting: it's never "just a cataract". J Anaesthesiol Clin Pharmacol 2012;28:520-3.

16. Lara AR, Schwarz MI. Diffuse alveolar hemorrhage. Chest 2010;137:1164-71.

17. Saeed AI, Quintana C, McGuire FR, Barker JA. Delayed presentation: negative pressure pulmonary hemorrhage. J Clin Anesth 2012;24:490-3.

18. Kim CA, Liu R, Hsia DW. Diffuse alveolar hemorrhage induced by sevoflurane. Ann Am Thorac Soc 2014;11:853-5. 